\title{
RESENHA
}

\section{RESENHA. Brasil, Século XXI - Por uma Nova Regionalização? Agentes, Processos e Escalas}

\author{
Ester Limonad, Rogério Haesbaert e Ruy Moreira (orgs.) \\ São Paulo, Max Limonad, 2004, 212 p.
}

Coletânea organizada por Ester Limonad, Rogério Haesbaert e Ruy Moreira, Brasil, século XXI- por uma nova regionalização? Agentes, processos e escalas é o resultado de um encontro de pesquisadores e especialistas da organização do espaço contemporâneo. Do começo ao fim somos convocados a repenșar a incorporação das variáveis do período nas diversas regiões brasileiras e a abandonar interpretações simplistas ou portadoras da força das idéias consolidadas. O mundo mudou, o Brasil mudou e estamos perante o desafio de encontrar esquemas interpretativos que sejam coerentes com a nossa época. A regionalização, como forma de análise e como forma de ação política, é posta em questão, nas suas definições e nos seus instrumentos. Duas regiões brasileiras, sobretudo, ficam sob a lente desses estudiosos: a Amazônia e o Sudeste, porém sem prejuízo da totalidade que é, permanentemente, um ponto de partida e um ponto de chegada das reflexões.

Correspondente à conferência de abertura, o texto de Bertha Becker chama a atenção sobre a formação de ilhas dinâmicas que alteram as antigas regiões e o papel do Estado e do planejamento territorial. Por essa razão, as macro-regiões já não constituem unidades aptas para as políticas de desenvolvimento. Se o Estado, em parceria com capitais internacionais, foi importante na constituição de redes na Amazônia, hoje, esses mesmos capitais estabelecem formas de cooperação com as populações tradicionais. Eis um dado novo numa região plena de especificidades, que conhece novos processos e agentes operando em escalas diversas. É o momento de implementar uma quarta revolução tecnológica para o bioma da floresta ama- 
zônica, baseada na biodiversidade e na biotecnologia. Um verdadeiro desafio para a pesquisa e a ação.

O texto de Tânia Bacelar de Araújo e outros autores procura ampliar o debate sobre a Política Nacional de Desenvolvimento Regional (PNDR), elaborada pelo Ministério da Integração Regional. Valorizando a cooperação, as visões e projetos da sociedade regional, em lugar de atrair exclusivamente as grandes corporações, essa política pretende desenvolver compensações territoriais, cuidando das áreas abandonadas pelas forças de mercado e evitando, assim, o acirramento das desigualdades socio-territoriais. Reivindica a escala nacional da ação na busca da coerência com o fenômeno social e para impedir uma profusão de localismos.

Ester Limonad indaga sobre a essência e intencionalidade da regionalização, para exorcizarmos, desse modo, o risco de naturalizar a escolha das variáveis e a aplicação das políticas. Assinalando a inexistência de limites precisos, princípio quase incontestado ao longo da história da geografia e de outras disciplinas territoriais, a autora se pergunta como definir a região? como regionalizar? Pelo seu conteúdo intencional, as regionalizações possíveis para um espaço são muitas e cabe a nós desvendar os propósitos que cada uma delas encarna. Vemos, no Brasil contemporâneo, uma regionalização funcional à atual divisão internacional do trabalho, que orienta o planejamento a reforçar a globalização.

O trabalho de Sandra Lencioni revela aspectos centrais da organização do espaço no Estado de São Paulo. Considerando uma falácia a idéia de descentralização industrial, reconhece um processo de desconcentração industrial no Sudeste e de industrialização de outras áreas do território nacional. A história não pode ser negligenciada. A criação da Região Metropolitana de Campinas não é resultado da chamada desindustrialização de São Paulo mas, ao contrário, fruto da sua expansão. Conforma-se uma cidade-região, cuja densidade industrial é elevada assim como os fluxos e interrelações de diversa natureza. É insuficiente falar de urbanização. Trata-se de um processo de metropolização que apresenta novos desafios para o planejamento.

No seu segundo trabalho, Ester Limonad contesta a idéia do esvaziamento e da relação parasitária entre o antigo Estado de Guanabara e o Estado do Rio de Janeiro. Se diminui a participação da cidade do Rio de Janeiro no PIB industrial, cresce, ao mesmo tempo, o setor financeiro e de serviços. Contudo, esse dado não deve ofuscar-nos na análise do território. A reformulação das atividades ligadas ao petróleo, a instalação de montadoras no interior, a privatização das estatais, o aumento dos domicílios de trabalhadores urbanos em áreas não-urbanas refuncionalizam, entre outros, a relação capital-interior, o espaço de produção em diversas escalas e evidenciam uma urbanização fragmentada.

Cláudio Egler aborda o papel das instituições na organização do território. O contexto de sua discussão considera o peso da região Sudeste no país, assim como o papel das redes urbanas na diferenciação regional. São essas diferenciações que definem novas institucionalidades relativas à participação nos fundos públicos e as 
respectivas pressões políticas. A implantação de regiões administrativas, uma regionalização dos governos estaduais, pode ser vista dessa perspectiva.

Ivaldo Lima acrescenta, a sua antiga preocupação sobre a divisão territorial da Amazônia, a busca das razões da atual agregação de frações do território. A criação de municípios com a respectiva formação de poderes locais definiu a Amazônia urbana, que acabou por conduzir a novas regionalizações. A constituição de redes está no cerne desse debate e deve ser vista, ao mesmo tempo, como ordem e desordem, construção e desconstrução de territórios. Formas de cooperação municipal e intermunicipal nascem nos insterstícios do pacto federativo e produzem rupturas escalares. É uma escala territorial insurgente.

Roberto Monte-Mór define como urbanização extensiva o processo que alcançou a quase totalidade do território brasileiro, inclusive a Amazônia. A articulação de centros industriais, fontes de matérias primas, transportes, energia e comunicações criou condições de produção e consumo próprias da modernidade. Esse é o processo que "permite compreender a rápida e intensa politização dos povos da floresta na Amazônia".

Ruy Moreira discute as reconfigurações que resultam das sucessivas divisões territoriais do trabalho: um espaço industrialmente disperso e indiferenciado até 1920, um período de progressiva concentração até 1950, um espaço industrialmente concentrado e diferenciado entre 1950 e 1970 e, a partir dessa década, uma centralização que se acompanha da desconcentração e diferenciação regional das indústrias. $\mathrm{Na}$ atual divisão do trabalho, o autor reconhece quatro grandes regiões, nas quais as empresas criam sua territorialidade e, assim, atentam contra a natureza nacional do espaço brasileiro. Nesse contexto, haverá alguma fonte de acumulação interna capaz de contrarrestar a centrifugação de uma economia global e financeira?

Analisando os espaços da desigualdade decorrentes da globalização, Jorge Luiz Barbosa faz ênfase nas perdas das conquistas da cidadania moderna. E alerta que, toda vez que os trabalhadores se organizam para reivindicar seus direitos, a política se torna um "ato de polícia" que permite, às classes dominantes, criar um "consenso imposto". A violência, porém, nasce do grau de concentração da renda nacional brasileira. O espaço social é seu prisma de análise.

Leila Christina Dias aborda criticamente o papel das redes na constituição do espaço brasileiro. A integração do mercado nacional pelas redes materiais se perfez, alguns anos mais tarde, com um sistema de telecomunicações, uma reforma financeira e um projeto tecno-científico. Assim, os bancos tornaram-se instrumento privilegiado do Estado na internacionalização da economia brasileira e na integração do mercado nacional. Mas, é preciso diferenciar a lógica das redes, nascida ao abrigo dos agentes hegemônicos, e a lógica dos territórios que pede o reconhecimento dos sujeitos da ação, isto é, a dimensão política da região e, em conseqüência, a regionalização como instrumento político da divisão do espaço. Novoś arranjos institucionais e espaciais definem, hoje, a região. 
Rogério Haesbaert lembra-nos que território e região têm sido conceitos indissociáveis na história das idéias e, hoje, ainda mais, quando se coloca o problema de como regionalizar num mundo em constante des-territorialização. Esta, mesmo que vinculada ao fenômeno da compressão tempo-espaço, não significa o fim das distâncias nem a superação do espaço pelo tempo. Trata-se de geometrias de poder criadoras de um espaço desigual. Todavia, o autor prefere falar de multiterritorialidades para caracterizar o processo contemporâneo: a predominância dos territórios-rede sobre os territórios-zona. A multiterritorialidade significa a possibilidade de conectar, aqui e agora, diversos territórios, seja por mobilidade concreta (física) ou informacional (ciberespaço). A regionalização pode ser vista como um processo de superposição de lógicas de área, lógicas reticulares e "i-lógicas" da exclusão. É dessa amálgama que resultam as especificidades regionais a serem apreendidas num exercício de regionalização, preocupado em incorporar o mais importante fluxo do presente, as pessoas.

Por fim e para propor uma reflexão à luz dos debates anteriores, Ana Clara Torres Ribeiro diferencia a "regionalização como fato" que independe da ação hegemônica do presente, e a "regionalização como ferramenta" dessa mesma ação. Na primeira acepção, a regionalização é compreendida a partir de um esforço de periodização e, na segunda, a região é, hoje, objeto do Estado, das corporações e dos movimentos sociais. A região encarna os interesses dos agentes diversos e a influência das esferas da vida coletiva. Essa expressão espacial que é um fato, pode também ser objeto de delimitação visando implementar uma ação.

Ao longo da coletânea, a regionalização é datada como movimento paralelo da sociedade e do território, produtor de diferenciações e, ao mesmo tempo, como critério (político) de divisão do espaço. É por isso que são reconhecidos os múltiplos eventos que, nos dias de hoje, impactam nas regiões e complicam a sua definição, tanto para a interpretação como para a ação. Um enfoque centrado apenas nas redes já demonstrou suas limitações. A aceleração contemporânea do fenômeno técnico cria nexos extrovertidos e um dinamismo complexo, tanto em regiões onde o peso da natureza é ainda significativo, quanto no dinamismo complexo do Sudeste. A multiplicidade de agentes com força e escala tão desigual, somada ao peso das idéias legitimadas, ofusca, tantas vezes, o entendimento do novo. A escala, vista como um problema de método e de ação, de história e de futuro, é um tema relevante no debate. A indústria contemporânea, cuja feição e dinâmica mudam em função do comando da finança e da informação, leva a rearranjos na região concentrada e, coloniza, de posse das novas variáveis, as áreas até recentemente "periféricas" do território. A expansão da produção agropecuária e industrial moderna cria uma nova geografia brasileira da qual participa um novo sistema urbano. A escala nacional de análise e ação não pode ser abandonada ao preço de erodir, ainda mais, os "filtros" políticos capazes de permitir as escolhas diante da globalização. 